\title{
Review \\ Clinical review: Long-term noninvasive ventilation
}

Dominique Robert and Laurent Argaud

Emergency and Medical Intensive Care Department, Edouard Herriot Hospital, Place d'Arsonval, Lyon, F-69008, France

Corresponding author: Laurent Argaud, laurent.argaud@chu-lyon.fr

Published: 26 March 2007

This article is online at http://ccforum.com/content/11/2/210

(c) 2007 BioMed Central Ltd
Critical Care 2007, 11:210 (doi:10.1186/cc5714)

\begin{abstract}
Noninvasive positive ventilation has undergone a remarkable evolution over the past decades and is assuming an important role in the management of both acute and chronic respiratory failure. Long-term ventilatory support should be considered a standard of care to treat selected patients following an intensive care unit (ICU) stay. In this setting, appropriate use of noninvasive ventilation can be expected to improve patient outcomes, reduce ICU admission, enhance patient comfort, and increase the efficiency of health care resource utilization. Current literature indicates that noninvasive ventilation improves and stabilizes the clinical course of many patients with chronic ventilatory failure. Noninvasive ventilation also permits long-term mechanical ventilation to be an acceptable option for patients who otherwise would not have been treated if tracheostomy were the only alternative. Nevertheless, these results appear to be better in patients with neuromuscular/parietal disorders than in chronic obstructive pulmonary disease. This clinical review will address the use of noninvasive ventilation (not including continuous positive airway pressure) mainly in diseases responsible for chronic hypoventilation (that is, restrictive disorders, including neuromuscular disease and lung disease) and incidentally in others such as obstructive sleep apnea or problems of central drive.
\end{abstract}

\section{Introduction}

After the successful use of tracheostomy and intermittent positive pressure ventilation (IPPV) in the 1950s to treat acute bulbar poliomyelitis [1], some patients were discharged at home with long-term mechanical ventilation via tracheostomy (invasive) or mouth piece (noninvasive) [2,3]. However, it was only in the 1980s after the introduction of noninvasive positive pressure ventilation (NIPPV) through facial interfaces in the intensive care unit (ICU) that long-term NIPPV was considered as a standard of care to treat selected patients following an ICU stay. NIPPV is now a predominant technique for long-term home ventilation [4]. It is also well recognized that NIPPV allows patients treated for acute failure from chronic respiratory insufficiency to be discharged from hospital and also prevents readmissions [5,6]. These beneficial effects have been reported for both chronic obstructive pulmonary disease (COPD) and neuromuscular/ parietal disorders [6]. Depending on the underlying diseases and the severity, IPPV is either continuously mandatory to avoid death in cases of complete or quasi-complete paralysis or is used nightly, producing enough improvement to allow free time during the daytime for spontaneous breathing. This clinical review will address the use of NIPPV (not including continuous positive airway pressure (CPAP)) in the different diseases for which it is currently proposed.

\section{Methods of NIPPV and their uses Interfaces}

The need to select an appropriate and properly fitted interface cannot be overemphasized due to its impact on the quality of ventilation [7]. The aim is to reach a compromise between different objectives: to minimize leaks, improve comfort and implement the mask easily. A wide variety of different factory-made masks of different designs, shapes, sizes and materials is now available. It is usually possible to find a mask that suits most individuals. Because of this, the initial practice of custom made interfaces for different individuals is now seldom needed, even if it remains probably the best interface $[7,8]$. There are currently four different types of interfaces: nasal masks, which are used predominantly $[8,9]$; facial masks covering the nose and the mouth; nasal pillows; and mouthpieces [9], which are now essentially indicated in the case of daytime ventilation [10]. Mouthpieces may afford an excellent interface to provide adjunct daytime ventilation in neuromuscular patients who are unable to maintain acceptable diurnal arterial blood gases without frequent intermittent periods of assistance. The mouthpiece is positioned close to the patient's mouth where it is intermittently captured to take a few assisted breaths from the ventilator and subsequently released. An advantage

$\mathrm{ABG}=$ arterial blood gas; $\mathrm{ALS}=$ amyotrophic lateral sclerosis; $\mathrm{BPAP}=$ bilevel positive airway pressure; COPD $=$ chronic obstructive pulmonary disease; $\mathrm{CPAP}=$ continuous positive airway pressure; $\mathrm{EtCO}_{2}=$ end-tidal $\mathrm{CO}_{2}$; ICU = intensive care unit; IPPV = intermittent positive pressure ventilation; NIPPV $=$ noninvasive positive pressure ventilation; $\mathrm{PaCO}_{2}=$ partial pressure of arterial carbon dioxide; $\mathrm{PaO}_{2}=$ partial pressure of arterial oxygen; $\mathrm{PEEP}=$ positive end-expiratory pressure; $\mathrm{SpO}_{2}=$ pulse oximetry; $\mathrm{TcCO}_{2}=$ transcutaneous $\mathrm{CO}_{2}$. 
of this is that the face is free from face-attached interfaces. Patients needing assistance night and day may use a combination of interfaces.

\section{Ventilators and modes for NIPPV}

Ventilators use one of two basic methods: volume-preset and pressure-preset [9]. With volume-preset, the ventilator always delivers the tidal volume that is set by the clinician, regardless of the patient's pulmonary system mechanics (compliance, resistance and active inspiration). However, leaks at the skinmask interface, or through the mouth when using a nasal mask, reduce the volume received by the patient. Conversely, with pressure-preset, changes in pulmonary mechanics directly influence the flow and the delivered tidal volume (lower or higher) since the ventilator delivers the set pressure throughout inspiration. In this case, leaks augment the flow and tend to maintain the tidal volume [11]. More recently, a third method has been proposed for both ICU and home ventilation. This is called pressure-preset/volume-targeted and aims to guarantee delivery of a tidal volume with the comfort of the pressure-preset method. At the present time, clinical evaluation of this third method remains poorly documented [12]. It is important to understand that NIPPV is dominated by both rapidly varying non-intentional leaks and the geometry and the resistance of the upper airway [13]. Obviously, leaks and airway resistance partly interact. In the face of these continuous changes the respective advantages and drawbacks of volume- and pressure-preset methods, which are opposite, make it difficult to predict their effects. The way inspiration begins and ends is initiated either by the ventilator or in response to a patient effort to do so, allowing one to define the main modes of ventilation: control, assistcontrol, and assist or spontaneous (assist or spontaneous possible only with pressure-preset).

Most home ventilators function according to only one of the methods, volume-preset or pressure-preset, but modern ones may deliver inspiration by both methods. Besides the classic circuitry, including two valves (on the inspiratory and expiratory limbs) alternately closing and opening, bilevel positive airway pressure (BPAP) ventilators are simpler and, therefore, lend themselves to home mechanical ventilation [14]. Inspiratory and expiratory pressures are alternatively established in a single circuit incorporating an intentional, calibrated leak located close to the patient or even on the mask. The theoretical disadvantage with such a circuit is the risk of variable $\mathrm{CO}_{2}$ rebreathing. However, concern about the risk of $\mathrm{CO}_{2}$ rebreathing has not been definitively documented [15], although the trend is to consider it as negligible provided positive expiratory pressure is applied in order to eliminate $\mathrm{CO}_{2}$ through the intentional leak (at least 2 to $4 \mathrm{cmH}_{2} \mathrm{O}$ ) [16]. Depending on the ventilator, all the different modes and refined settings, and even closed-loop modes usually applied in the ICU, are more or less available. Some ventilators may analyze ventilation in an on-going manner and keep the data in internal memory for further assessment. The general objective is to provide many possible capabilities in order to have enough tools to adapt and optimize patientmachine synchronization. While conceptually attractive, sufficient studies have not been performed to document or refute the advantages of such complexity in the context of noninvasive home ventilation.

\section{Choice of the ventilator and mode}

Many clinicians currently prefer a pressure-preset ventilator in assist mode as the first choice with a view to offering the best synchronization [4]. In fact, in the studies comparing volume and pressure-preset ventilators, no clear differences in the correction of hypoventilation in short-term studies $[17,18]$ and long-term outcomes $[19,20]$ have been shown. This is understandable since leaks and resistance changes during NIPPV alternate very quickly and when the pressure target is well achieved, the volume target is not, and vice versa. However, it is important to remain flexible by trying alternative approaches if problems occur with one or the other type of ventilator.

Additionally, even if new generations of BPAP ventilators tend to contain batteries, it should be noted that these batteries most often provide autonomy of only short duration. This would limit security and mobility of neuromuscular patients with hypoventilation and then shift the preference to the volume ventilator.

\section{Criteria to consider when deciding on the implementation of NIPPV Signs and symptoms of hypoventilation}

The presence of clinical symptoms and/or physiological markers of hypoventilation are useful in identifying clinical severity as it relates to therapeutic decision-making with regard to initiation of nocturnal NIPPV. In the course of a typically progressing disease, two successive steps occur more or less rapidly: nocturnal hypoventilation that is reversible during waking hours associated with none or a few clinical symptoms; and nocturnal and daytime hypoventilation associated with clinical symptoms that show a low respiratory reserve and should be considered an unstable state with increased susceptibility to life-threatening acute ventilatory failure that may be triggered by what may otherwise be trivial additional factors [21,22]. A sleep study continuously recording $\mathrm{CO}_{2}$ (end-tidal $\left(\mathrm{EtCO}_{2}\right)$ or transcutaneous $\left(\mathrm{TcCO}_{2}\right)$ ) and/or pulse oximetry $\left(\mathrm{SpO}_{2}\right)$ is required to document nocturnal hypoventilation, which may occur throughout all sleep stages but in some cases exclusively during rapid eye movement sleep. Daytime hypoventilation is defined by abnormally elevated partial pressure of arterial carbon dioxide $\left(\mathrm{PaCO}_{2}\right)$, a high serum bicarbonate level and a relatively normal $\mathrm{pH}$ with associated reduction of the partial pressure of arterial oxygen $\left(\mathrm{PaO}_{2}\right)$. Chronic daytime hypoventilation is an important indicator invariably associated with sleep-related hypoventilation. Thus, in the presence of diurnal hypoventilation, the reason for overnight recording is only to 
Table 1

\section{Clinical features frequently associated with alveolar hypoventilation}

Shortness of breath during activities of daily living in the absence of paralysis

Orthopnea in patients with disordered diaphragmatic dysfunction

Poor sleep quality: insomnia, nightmares and frequent arousals

Nocturnal or early morning headaches

Daytime fatigue, drowsiness and sleepiness, loss of energy

Decrease in intellectual performance

Loss of appetite and weight loss

Appearance of recurrent complications: respiratory infections

Clinical signs of cor pulmonale

rule out obstructive or central apnea. Clinical symptoms indicating consequences of hypoventilation (Table 1) must be carefully evaluated since, even when modest, they are important for the appreciation of disease severity and prognosis and in the indication of NIPPV. Pulmonary function tests help define and quantify the ventilatory-respiratory disease but have low predictive values for chronic sleeprelated hypoventilation in individual patients except in those with neuromuscular disease. Indeed, in Duchenne muscular dystrophy, hypoventilation appears only during rapid eye movement sleep, all night, or during the daytime when supine inspiratory vital capacity is $<40 \%,<25 \%$ and $<12 \%$, respectively [21]. Similarly, a peak cough flow $<160 \mathrm{I} / \mathrm{min}$, related to expiratory muscle deficit, means an increased risk of accumulation of secretions that may worsen hypoventilation and trigger acute failure [23]. It is crucial to note that isolated reduced $\mathrm{PaO}_{2}$ does not require mechanical ventilation but only supplemental oxygen because it does not indicate hypoventilation but only a mismatching of ventilation and perfusion.

\section{Diseases that may potentially be treated with NIPPV}

The principal diseases that may be addressed using NIPPV therapy are shown in Table 2. Except for those due to respiratory control or upper airway abnormalities, all may become severe enough to cause alveolar hypoventilation during sleep and daytime and eventually may impair the quality of life and threaten life. In neuromuscular disorders, it is important to consider the progressiveness according to each type of disease and the individual concerned.

\section{Survival with NIPPV in different diseases}

NIPPV efficacy in terms of survival compared to control treatment is important information required in order to adequately discuss NIPPV. Besides a few randomized control trials [24-27], this information comes from retrospective series compared to the usual prognosis [20,28-31]. In order to extend the analysis, it is also possible to take into account results obtained with either negative pressure ventilation [32] or tracheostomy [2]. These are informative enough and generally accepted by the medical community even if conclusions derived from them are refutable in terms of evidence-based medicine. In neuromuscular disease, NIPPV always increases survival. Approximate median increased survival times depend on the age of the patient when starting NIPPV and the comorbidities present (including extended paralysis): very long ( $>20$ years) in the sequelae of poliomyelitis; long (10 years) in spinal muscular atrophy type 2 and 3, Duchenne muscular dystrophy, and acid maltase deficiency; short (4 years) in myotonic dystrophy; and very short (1 year) in amyotrophic lateral sclerosis (ALS). In cases of chest-wall abnormalities, NIPPV also prolongs life: 15 years in kyphosis and 7 years in the sequelae of tuberculosis. No data support a positive effect on survival in lung diseases: in COPD patients randomized trials are negative $[25,26,32]$, and data are too scarce in cystic fibrosis or for bronchiectasis patients. However, we must note that the negative results in the trials in COPD may be related to insufficient ventilation due to a too low driving pressure.

\section{Circumstances and indications for NIPPV}

In clinical practice, NIPPV is initiated either electively or in the context of acute ventilatory failure initially treated invasively with translaryngeal intubation or noninvasively with facial interfaces [33]. In the latter circumstances, the long-term necessity for NIPPV should be reevaluated after weeks or months during follow-up since the indications for NIPPV may change as the clinical conditions improve or not. In cases of chronic and stable awake hypoventilation, the main criteria for predicting the need for NIPPV are advanced severity with clinical symptoms of hypoventilation plus a balance of several other issues, including: the main primary process explaining the hypoventilation - mechanical or lung deficit; whether the natural rate of progression has been a few years or dozens of years; the clinical severity at the time of decision making; actual symptoms and history of acute-subacute failure in the previous months; and the patient's willingness, including the family and social environment, to undertake this therapy.

Indications for NIPPV are outlined in Table 3. NIPPV is strongly indicated in patients with chest wall and neuromuscular disorders in the presence of clinical symptoms attributable to diurnal hypoventilation [34-37]. There are no validated values above which NIPPV is definitely indicated; however, many clinicians consider treatment in scoliosis and sequelae of tuberculosis with awake $\mathrm{PaCO}_{2}>50$ to $55 \mathrm{mmHg}$ and $\mathrm{PaO}_{2}<60 \mathrm{mmHg}$, and in neuromuscular disease with a $\mathrm{PaCO}_{2}$ around 45 to $50 \mathrm{mmHg}$ and $\mathrm{PaO}_{2}<70 \mathrm{mmHg}$. In cases with clear clinical symptoms, less severe values may be considered as an indication to start NIPPV [35]. Conversely, in COPD and probably in other lung diseases, diurnal hypoventilation does not support the unequivocal utility of NIPPV $[38,39]$. Nevertheless, this question remains open since the 
Table 2

\section{Main diseases that can benefit from NIPPV classified according to the cause and progressiveness of the respiratory impairment}

Parietal disorders (PFT abnormal; $\downarrow$ VC,$\downarrow$ FEV $1, \rightarrow \mathrm{FEV} 1 / \mathrm{VC}, \downarrow \mathrm{RV}$ $\downarrow$ TLC)

Chest wal

Kyphoscoliosis

Sequelae of tuberculosis

No worsening

Obesity hypoventilation

syndrome

Neuromuscular disorders

Spinal muscular atrophy

No worsening

Acid maltase deficit

Duchenne muscular dystrophy

Slow worsening ( $>15$ years)

Intermediate worsening

( 5 to 15 years)

Myotonic myopathy

Intermediate worsening

( 5 to 15 years)

Amyotrophic lateral sclerosis

Rapid worsening

( 0 to 3 years)

Lung diseases (PFT abnormal; $\rightarrow$ or $\downarrow$ VC,$\downarrow$ FEV $1, \downarrow$ FEV1/VC,

$\uparrow \mathrm{RV}, \uparrow \mathrm{TLC})$

COPD

Continuous worsening

Bronchiectasis, cystic fibrosis

Continuous worsening

Predominant ventilatory control abnormalities (PFT normal)

Ondine's curse Improvement?

Cheyne-Stokes breathing Depends on heart failure

Upper airway abnormalities (PFT normal)

Obstructive sleep apnea

No worsening

Symbols indicate actual compared to theoretical values: $\downarrow$, decrease;

$\uparrow$, increase; $\rightarrow$, normal. COPD, chronic obstructive pulmonary disease; FEV1, forced expiratory volume in 1 second; NIPPV, noninvasive positive pressure ventilation; PFT, pulmonary function test; RV, residual volume; TLC, total lung capacity; VC, vital capacity.

clinical trials are underpowered and secondary parameters, such as some components of the quality of life or hospitalization days, may have improved. Some observational series suggest better results [40,41]. Presently, we may admit NIPPV as an option in COPD patients with symptoms of hypoventilation contributing to recurrence of acute-subacute failure, provided that long-term oxygen and drug therapy have already been optimally adjusted. During early stages with only isolated nocturnal hypoventilation, NIPPV is not mandatory but could be optional in kyphoscoliosis and neuromuscular diseases [42]. In the latter, when worsening is both inevitable and rapid (for example, ALS), NIPPV is valuable at an early stage provided that this is an acceptable therapeutic option for the patient.

NIPPV use in some other diseases may also deserve consideration even if clinical experience remains inconclusive. Obesity hypoventilation syndrome is dominated by morbid obesity impeding ventilation, frequent obstructive apnea and more or less reversible decreased reactivity of the respiratory centers [43]. In acute-subacute as in chronic situations, NIPPV has been shown to reverse hypoventilation $[44,45]$. However, considering the high prevalence of obstructive apnea, CPAP is a simpler and efficient treatment. In addition, CPAP reduces the resistance of the pharynx, which leads to a light reduction of the work of breathing. This may be another reason for the reversal of the hypoventilation. Cheyne-Stokes breathing with central and obstructive apnea in the context of severe cardiac insufficiency has been shown to negatively influence the clinical situation and survival [46]. Conventional NIPPV or a new modality, such as adaptive servo-ventilation, has been shown to alleviate apnea and improve cardiac function $[47,48]$. Nevertheless, no conclusion about the utility of nocturnal NIPPV in terms of survival and main outcomes is available. In addition, a recent large study comparing oxygen and CPAP, which also alleviates apnea and improves cardiac function, does not prove the clinical superiority of CPAP in terms of survival [49]. Pure obstructive sleep apneas in the context of obstructive sleep apnea could be suppressed with NIPPV. Some authors have proposed NIPPV as a second-line treatment in the case of CPAP failure. However, this is not supported with enough conclusive study to be recommended [50]. Ondine's curse, in children, is characterized by the lack of metabolic response of the respiratory centers during sleep and is responsible for severe nocturnal hypoventilation. The usual treatment is tracheostomy and nocturnal ventilation. Some clinical experience suggests that, after years, tracheostomy might be converted in some cases to nocturnal NIPPV. Obviously, such options must remain in the hands of specialized teams [51].

\section{Management of NIPPV Initiation and settings for nocturnal ventilation}

The main goal of NIPPV, which in the best circumstances is used solely during the night, is to improve arterial blood gases up to nearly normal values without discomfort and sleep disruption. However, day time mechanical ventilation in chronic respiratory insufficiency is as good as night time ventilation. The reduction of hypercapnia depends more on the duration of the ventilation than on whether the patient is asleep or awake [52]. The objective when there is residual muscle ability to breathe is to provide enough improvement to allow comfortable time off the ventilator. Even if there is no absolute recommendation, it is good general practice to proceed in three steps. The first step consists of selecting and adjusting the ventilator settings while the patient is awake, insuring physiological adequacy and patient comfort for at least one or two hours. One study, done on awake cystic fibrosis patients, found that clinical observation is as efficient as the use of physiological measurements, including esophageal pressure, in setting the ventilator parameters [53]. Another in patients with COPD and neuromuscular disease has shown that using physiological measurements does not improve ventilation during the day but improves ventilation and sleep quality during the night $[54,55]$. 
Table 3

\begin{tabular}{|c|c|c|c|c|}
\hline Disease & $\begin{array}{c}\text { Symptoms and } \\
\text { night/day } \mathrm{CO}_{2} \uparrow\end{array}$ & $\begin{array}{l}\text { Symptoms and } \\
\text { only night } \mathrm{CO}_{2} \uparrow\end{array}$ & $\begin{array}{l}\text { No/limited symptoms } \\
\text { but night/day } \mathrm{CO}_{2} \uparrow\end{array}$ & $\begin{array}{c}\text { Usual daily duration } \\
\text { of NIPPV }\end{array}$ \\
\hline Scoliosis & Yes & Yes & Perhaps & $<12$ hours \\
\hline Tuberculosis & Yes & Yes & Perhaps & $<12$ hours \\
\hline Neuromuscular stable or slow & Yes & Perhaps & Perhaps & $18-24$ hours \\
\hline Neuromuscular intermediate & Yes & Perhaps & Perhaps & $18-24$ hours \\
\hline Neuromuscular rapid & Yes & Yes & Yes & 24 hours \\
\hline COPD & Perhaps & No & No & 12 hours \\
\hline Bronchiectasis/cystic fibrosis & Perhaps & No & No & $18-24$ hours \\
\hline Obesity hypoventilation & Perhaps & Perhaps & No & $<12$ hours \\
\hline
\end{tabular}

$\uparrow$, Increase; COPD, chronic obstructive pulmonary disease ; NIPPV, noninvasive positive pressure ventilation.

In the second step, the clinician should judge adequacy when the patient is napping and/or during nocturnal use. To complete this step, different options according to the resources available in each center could be used. Arterial blood gas (ABG) measurements would seem ideal; however, one or a few samples during the night do not represent the rapid changes observed during several continuous hours of sleep, and the invasiveness of sampling has led most clinicians to noninvasively monitor different parameters. Ideally, a complete polysomnogram recording $\mathrm{SpO}_{2}$ and $\mathrm{TcCO}_{2}$ or $\mathrm{EtCO}_{2}$, airflow, tidal volume, airway pressure, rib cage and abdomen excursion, and sleep staging permits a complete assessment [56]. When resources are not available to perform these detailed recordings, fewer measurements during overnight recordings remain informative. However, the minimal requirement is to record $\mathrm{SpO}_{2}$ overnight in room air, assessing whether the normalization of $\mathrm{SpO}_{2}$ accompanies a normalization, or at least an improvement, of $\mathrm{PaCO}_{2}$. In addition, data related to patient tolerance, comfort, sleep quality and well-being should be obtained.

The third step is carried out after several nights of NIPPV and consists of looking for a reduction in $\mathrm{PaCO}_{2}$ and augmentation of $\mathrm{PaO}_{2}$, without dyspnea, during the day when free from ventilation to confirm that the settings are adequate. This also gives information about the necessity or not to add daylight hours of NIPPV (at first during napping and more when necessary). If the results are not satisfactory, alterations must be made to the settings and possibly the mask and the ventilator, and the effects of these checked again. In most cases, a few days are necessary to achieve success.

If one uses assist pressure-preset ventilation, $10 \mathrm{cmH}_{2} \mathrm{O}$ of inspiratory pressure support is a suggested starting point. If necessary, the pressure level is progressively increased to achieve evidence of improvement. Pressure support higher than $20 \mathrm{cmH}_{2} \mathrm{O}$ is rarely necessary. Nevertheless, one observational series reports good results in COPD patients ventilated with higher $\left(28 \mathrm{cmH}_{2} \mathrm{O}\right)$ pressure [41]. In COPD, the addition of an expiratory positive pressure (positive endexpiratory pressure (PEEP) or expiratory positive airway pressure (EPAP)), also necessary to decrease the rebreathing with BPAP ventilators, should conceptually improve patient triggering when intrinsic PEEP exists [57]; however, there is no long-term study proving its clinical usefulness. Depending on the ventilator capabilities and observations made of how the patient and ventilator do together, more subtle settings concerning triggers, initial flow, and inspiratory time limit could be tried. A backup frequency set close to the spontaneous frequency of the patient during sleep is a reasonable substitute to avoid central apnea induced by transitory but repeated hyperventilation exceeding the apnea threshold [58].

When employing a volume-preset ventilator, the initial suggested settings may be established by adjusting the frequency of ventilator-delivered breaths so that it approximates the patient's spontaneous breathing frequency during sleep, an inspiratory time/total breathing cycle time between 0.33 and 0.50 and a relatively high tidal volume of around 10 to $15 \mathrm{ml} / \mathrm{kg}$ to insure sufficient tidal volume in case of leaks [59].

Supplemental oxygen should be added into the ventilator circuit in those patients requiring oxygen while awake due to lung parenchyma diseases (for example, COPD, cystic fibrosis, bronchiectasis). In the absence of parenchymal disease it is only after trying to optimize all technical parameters that residual desaturation may justify additional oxygen bled into the ventilator circuit during sleep [60].

\section{Continuous NIPPV}

In neuromuscular diseases (and to a lesser degree in endstage lung diseases), ventilator dependency may be total when starting NIPPV or may progressively increase following the gradual worsening of the disease. In cases of continuous 
need for ventilation, NIPPV could be used provided that interfaces are alternated night and day and assisted coughing is made available $[37,61]$. Only a very well trained team that is completely informed and conscious of the constraints and dangers involved may take such an approach in patients. Such application has been reported by different teams in stable neuromuscular patients, such as those with a sequelae of poliomyelitis, high-level spinal cord injury or Duchenne muscular dystrophy $[10,62]$. Alternatively, a tracheostomy may be performed to facilitate ventilatory assistance and secretion removal.

There is no clear answer as to whether, and beyond what duration, a totally ventilator-dependent patient is better or more safely ventilated by tracheostomy or NIPPV $[35,63,64]$. This debate will probably continue and, in the end, the decision to indicate NIPPV or to convert to tracheostomy is highly dependent on the philosophy and capabilities of the clinical team as well as that of the patient and their family environmental preferences. It is essential that discussion of such issues be started as early as possible in the patient's course, well before the imperative arises.

Swallowing dysfunction, which is responsible for frequent and massive aspirations and pneumonia and is observed during the course of ALS (frequent occurrence and is due to bulbar origin) or Duchenne muscular dystrophy (occurs seldomly and is due to muscle weakness), is an imperative indication for tracheostomy to prolong survival, although tracheostomy causes major difficulties for communication and reduces opportunities for personal interactions, leading to a locked-in state [64]. In this context, NIPPV, which may be easily stopped, could be the most reasonable option in cases of rapidly devastating diseases like ALS, and can be considered by both the patient and medical team as a limitation of care or a palliative approach [65]. This was confirmed in a study in which NIPPV in ALS patients with bulbar symptoms do not increase survival longer than controls [27].

\section{Follow-up}

Clinical follow-up and daytime ABG measurements (or their surrogates) should be conducted regularly (twice per year, for example). When possible, recordings during sleep when on NIPPV, identical to those taken when initiating NIPPV, are useful. At any time when there are unsatisfactory results, such as recurrence of clinical symptoms or hypoventilation on $A B G$, inadequate NIPPV must be suspected and objective evaluation during sleep must be undertaken. At the very least, overnight oximetry must be done. When NIPPV is determined to be suboptimal, a change in ventilator modality or setting and a review of the mask fitting may be indicated. Increasing the total duration of NIPPV use per day should also be considered, particularly when the underlying disease has progressed. Masks have to be regularly checked and changed or adapted as needed.

\section{Management of complications}

Air leaks during NIPPV

To some degree, leaks are present when using nasal NIPPV during sleep in all patients. The major potential adverse effects of such leaks are reduced efficiency of ventilation and sleep fragmentation $[66,67]$. A variety of measures, more or less efficacious, have been suggested to address problematic leaks. These include preventing neck flexion, reclining in a semi-recumbent position, discouraging the mouth from opening by use of a chin strap [67] or a cervical collar, switching to pressure-preset mode [59], decreasing the peak inspiratory pressure, increasing the delivered volume [11], optimizing the interface $[7,8]$, and possibly switching to nasal pillows or a full face mask [68]. The effectiveness of these measures must be confirmed during sleep recordings.

Nasal dryness, congestion, and rhinitis

With reference to the CPAP literature, the side effects of nasal dryness, congestion, and rhinitis are related to a defect of humidification promoted by air leaks [69]. For patients with nasal and mouth dryness, a cold passover or a heated humidifier (the latter is more effective) can be used [70]. Heat/moisture exchangers are not well adapted in cases of leaks since the 'dry' flow from the ventilator is higher than the 'dampened' flow returning from the patient. In a large series, a minority of patients needed humidifiers [9].

\section{Aerophagia}

Aerophagia, or swallowing air, is frequently reported by patients but is rarely intolerable [71]. Minor clinical signs are eructation, flatulence and abdominal discomfort. Aerophagia is usually dependent on the level of inspiratory pressure and is more commonly seen when using volume and/or mouthpiece ventilation and in the care of patients with neuromuscular disease. The incidence decreases if the peak inspiratory pressure is kept below $25 \mathrm{cmH}_{2} \mathrm{O}$ pressure.

\section{NIPPV effects (other than survival) and related mechanisms \\ During ventilatory assistance}

As expected, when under NIPPV, ventilation and gas exchange are improved in all types of disease [19,72,73], even if significant episodes of transient hypoventilation related to mouth leaks may appear [66,67]. Duration of sleep is augmented without clear changes in its quality $[65,74]$. Respiratory muscles are normally put at rest but there are many exceptions due to air leaks and patient-ventilator asynchrony [75].

\section{After ventilation}

When spontaneous ventilation exists, and in the absence of major lung disease, gas exchange remains improved after NIPPV is stopped. This may persist for hours and even days before reappearance of hypoventilation [76]. The improvement reported in many studies is important in chestwall and neuromuscular diseases but inconsistent in COPD 
[72,77]. Certainly, NIPPV can account for improvements in clinical symptoms such as general well-being, appetite, exercise capability, headaches, ankle edema, and resurgence of acute failure, as well as decreasing hospitalization, increasing quality of life [78] and improving survival.

Three main explanations for these improvements after NIPPV have been proposed: improved respiratory muscle strength, resetting of the chemoreceptors, and decrease of the ventilatory load. The first hypothesis suggests that ventilatory assistance rests the respiratory muscles, thereby reversing fatigue. Indeed, inspiratory force has been found to be significantly augmented in a few studies $[30,79]$. The second hypothesis suggests that, in response to chronic hypercapnia and hypoxia, the chemoreceptors commanding the respiratory centers change their set point, which perpetuates hypoventilation rather than attempting to generate non-sustainable ventilatory muscle efforts [80]. The resumption of better ventilation during NIPPV would reset the centers to more normal values. The third hypothesis suggests that an improvement in respiratory chest-wall and/or lung compliance, under the effects of positive pressure ventilation, would reduce the ventilatory load and increase the efficiency of the muscles. In the studies done on scoliosis, vital capacity significantly increased $[30,79]$; however, in other diseases, including neuromuscular patients, the vital capacity remained unchanged. In one study, chest-wall and lung compliance did not change even though there was a nonsignificant trend towards an increase [81]. Furthermore, periodic hyperinsufflation using higher inspiratory pressures for a few minutes in scoliosis [82] and ALS [83] patients revealed an increase in compliance. It seems probable that, even if the mechanisms that explain the efficacy of NIPPV are imperfectly understood, several factors, even if not individually significant, change and interact together to improve alveolar ventilation. The minimum mandatory duration of assistance is not clearly known. However, a relationship between a decrease in $\mathrm{PaCO}_{2}$ and the pressure to ventilate has been found [79]. Finally, one study reports a significant decrease in pulmonary arterial hypertension, which obviously favors clinical improvement [84].

In COPD patients, the absence of clinical results compared to those obtained for scoliosis and neuromuscular disease, even if resetting of the respiratory centers has been shown [85], could be explained by the relatively low impairment of respiratory muscles and the importance of the lesions of the lung itself and its progressiveness.

\section{Conclusions}

Chronic ventilatory support using NIPPV improves and stabilizes the clinical course of many patients with chronic ventilatory failure. The results appear to be good in patients with restrictive disorders and poor in COPD. Among the neuromuscular disorders results are better in the slowly progressing ones. The benefit of NIPPV is reflected by improvements in survival, blood gas composition and clinical stability, which help avoid the risk of acute failure and/or ICU admissions. Due to its relative simplicity and its non-invasive nature, NIPPV permits long-term mechanical ventilation to be an acceptable option for patients who otherwise would not have been treated if tracheostomy were the only alternative. In this way, nocturnal NIPPV represents a huge advance.

\section{Competing interests}

The authors declare that they have no competing interests.

\section{References}

1. Severinghaus JW, Astrup P, Murray JF: Blood gas analysis and critical care medicine. Am J Respir Crit Care Med 1998, 157: S114-S122.

2. Robert D, Gerard M, Leger P, Buffat J, Jennequin J, Holzapfel L, Mercatello A, Salamand, Bertoy A: Permanent mechanical ventilation at home via a tracheotomy in chronic respiratory insufficiency. Rev Fr Mal Respir 1983, 11:923-936.

3. Bach JR, Alba AS, Bohatiuk G, Saporito L, Lee M: Mouth intermittent positive pressure ventilation in the management of postpolio respiratory insufficiency. Chest 1987, 91:859-864.

4. Lloyd-Owen SJ, Donaldson GC, Ambrosino N, Escarabill J, Farre R, Fauroux B, Robert D, Schoenhofer B, Simonds AK, Wedzicha JA: Patterns of home mechanical ventilation use in Europe: results from the Eurovent survey. Eur Respir J 2005, 25:10251031.

5. American Thoracic Society: International Consensus conferences in intensive care medicine: noninvasive positive pressure ventilation in acute respiratory failure. Am J Respir Crit Care Med 2001, 163:283-291.

6. Make BJ, Hill NS, Goldberg Al, Bach JR, Griner GJ, Dunne PE, Gilmartin ME, Heffner JE, Kacmarek R, Keens TG, et al.: Mechanical ventilation beyond the intensive care unit. Report of a consensus conference of the American College of Chest Physicians. Chest 1998, 113:289S-344S.

7. Elliott MW: The interface: crucial for successful noninvasive ventilation. Eur Respir J 2004, 23:7-8.

8. Leger SS, Leger P: The art of interface. Tools for administering noninvasive ventilation. Med Klin 1999, 94:35-39.

9. Schonhofer B, Sortor-Leger S: Equipment needs for noninvasive mechanical ventilation. Eur Respir J 2002, 20:1029-1036.

10. Bach JR, Alba AS, Saporito LR: Intermittent positive pressure ventilation via the mouth as an alternative to tracheostomy for 257 ventilators users. Chest 1993, 103:174-182.

11. Tuggey JM, Elliott MW: Titration of non-invasive positive pressure ventilation in chronic respiratory failure. Respir Med 2006, 100:1262-1269.

12. Storre JH, Seuthe B, Fiechter R, Milioglou S, Dreher M, Sorichter $\mathrm{S}$, Windish W: Average volume-assured pressure support in obesity hypoventilation: A randomized crossover trial. Chest 2006, 130:815-821.

13. Jounieaux V, Aubert G, Dury M, Delquste $P$, Rodenstein DO: Effects of nasal positive-pressure hyperventilation on the glottis in normal sleeping subjects. J App/ Physiol 1995, 79: 186-193.

14. Sanders MH, Kern N: Obstructive sleep apnea treated by independently adjusted inspiratory and expiratory positive airway pressures via nasal mask. Physiologic and clinical implications. Chest 1990, 98:317-324.

15. Schettino GP, Chatmongkolchart S, Hess DR, Kacmarek RM: Position of exhalation port and mask design affect $\mathrm{CO} 2$ rebreathing during noninvasive positive pressure ventilation. Crit Care Med 2003, 31:2178-2182.

16. Hill N: What mask for noninvasive ventilation: is deadspace an issue? Crit Care Med 2003, 31:2247-2248.

17. Cinnella G, Conti G, Lofaso $F$, Lorino $H$, Harf $A$, Lemaire $F$, Brochard L: Effects of assisted ventilation on the work of breathing: volume-controlled versus pressure-controlled ventilation. Am J Respir Crit Care Med 1996, 153:1025-1033.

18. Tuggey JM, Elliott MW: Randomised crossover study of pressure and volume non-invasive ventilation in chest wall deformity. Thorax 2005, 60:859-864. 
19. Schonhofer B, Sonneborn M, Haidl P, Bohrer H, Kohler D: Comparison of two different modes for noninvasive mechanical ventilation in chronic respiratory failure: volume versus pressure controlled device. Eur Respir J 1997, 10:184-191.

20. Janssens JP, Derivaz S, Breitenstein E, De Muralt B, Fitting JW, Chevrolet JC, Rochat $\mathrm{T}$ : Changing patterns in long-term noninvasive ventilation: a 7-year prospective study in the Geneva Lake area. Chest 2003, 123:67-79.

21. Ragette R, Mellies U, Schwake C, Voit T, Teschler H: Patterns and predictors of sleep disordered breathing in primary myopathies. Thorax 2002, 57:724-728.

22. Lo Coco D, Marchese S, Corrao S, Cettina Pesco M, La Bella V, Picolli F, Lo Coco A: Development of chronic hypoventilation in amyotrophic lateral sclerosis patients. Respir Med 2006, 100: 1028-1036

23. Bach JR: Update and perspective on noninvasive respiratory muscle aids. Part 2: The expiratory aids. Chest 1994, 105: 1538-1544.

24. Pinto AC, Evangelista T, Carvalho M, Alves MA, Sales Luis ML: Respiratory assistance with a non-invasive ventilator (Bipap) in MND/ALS patients: survival rates in a controlled trial. $J$ Neurol Sci 1995, 129(Suppl):19-26.

25. Clini E, Sturani C, Rossi A, Viaggi S, Corrado A, Donner CF, Ambrosino N; Rehabilitation and Chronic Care Study Group, Itilian Association of Hospital Pülmonologists (AIPO): The Italian multicentre study on noninvasive ventilation in chronic obstructive pulmonary disease patients. Eur Respir J 2002, 20: 529-538.

26. Casanova C, Celli BR, Tost L, Soriano E, Abreu J, Velasco V, Santolaria F: Long-term controlled trial of nocturnal nasal positive pressure ventilation in patients with severe COPD. Chest 2000, 118:1582-1590.

27. Bourke SC, Tomlinson M, Williams TL, Bullock RE, Shaw PJ, Gibson GJ: Effects of non-invasive ventilation on survival and quality of life in patients with amyotrophic lateral sclerosis: a randomised controlled trial. Lancet Neuro/ 2006, 5:140-147.

28. Simonds AK, Elliott MW: Outcome of domiciliary nasal intermittent positive pressure ventilation in restrictive and obstructive disorders. Thorax 1995, 50:604-609.

29. Aboussouan LS, Khan SU, Meeker DP, Stelmach K, Mitsumoto H: Effect of noninvasive positive-pressure ventilation on survival in amyotrophic lateral sclerosis. Ann Intern Med 1997, 127: 450-453.

30. Gonzalez C, Ferris G, Diaz J, Fontana I, Nunez J, Marin J: Kyphoscoliotic ventilatory insufficiency: effects of long-term intermittent positive-pressure ventilation. Chest 2003, 124: 857-862.

31. Farrero E, Prats E, Povedano M, Martinez-Matos JA, Manresa F, Escarrabill J: Survival in amyotrophic lateral sclerosis with home mechanical ventilation: the impact of systematic respiratory assessment and bulbar involvement. Chest 2005, 127: 2132-2138.

32. Shapiro SH, Ernst P, Gray-Donald K, Martin JG, Wood-Dauphinee S, Beaupre A, Spitzer WO, Macklem PT: Effect of negative pressure ventilation in severe chronic obstructive pulmonary disease. Lancet 1992, 340:1425-1429.

33. Keenan SP, Sinuff T, Cook DJ, Hill NS: Which patients with acute exacerbation of chronic obstructive pulmonary disease benefit from noninvasive positive-pressure ventilation? A systematic review of the literature. Ann Intern Med 2003, 138:861870.

34. Robert $D$, Willig TN, Leger P, Paulus J: Long-term nasal ventilation in neuromuscular disorders: report of a consensus conference. Eur Respir J 1993, 6:599-606.

35. Shneerson JM, Simonds AK: Noninvasive ventilation for chest wall and neuromuscular disorders. Eur Respir J 2002, 20:480487.

36. Simonds AK, Ward S, Heather S, Bush A, Muntoni F: Outcome of paediatric domiciliary mask ventilation in neuromuscular and skeletal disease. Eur Respir J 2000, 16:476-481.

37. Finder JD, Birnkrant D, Carl J, Farber HJ, Gozal D, lannaccone ST, Kovesi T, Kravitz RM, Pannitch H, Schramm M, et al:: Respiratory care of the patient with Duchenne muscular dystrophy: ATS consensus statement. Am J Respir Crit Care Med 2004, 170: 456-465.

38. Wijkstra PJ, Lacasse Y, Guyatt GH, Goldstein RS: Nocturnal non-invasive positive pressure ventilation for stable chronic obstructive pulmonary disease. Cochrane Database Syst Rev 2002, CD002878.

39. Wiikstra PJ, Lacasse Y, Guyatt GH, Casanova C, Gay PC Meecham Jones J, Goldstein RS: A meta-analysis of nocturnal noninvasive positive pressure ventilation in patients with stable COPD. Chest 2003, 124:337-343.

40. Diaz O, Begin P, Andresen M, Pietro ME, Castillo C, Jorquera J, Lisboa C: Physiological and clinical effects of diurnal noninvasive ventilation in hypercapnic COPD. Eur Respir J 2005, 26: 1016-1023.

41. Windisch W, Kostic S, Dreher M, Virchow JC Jr, Sorichter S: Outcome of patients with stable COPD receiving controlled noninvasive positive pressure ventilation aimed at a maximal reduction of $\mathrm{Pa}(\mathrm{CO} 2)$. Chest 2005, 128:657-662.

42. Ward S, Chatwin M, Heather S, Simonds AK: Randomised controlled trial of non-invasive ventilation (NIV) for nocturnal hypoventilation in neuromuscular and chest wall disease patients with daytime normocapnia. Thorax 2005, 60:10191024.

43. Olson AL, Zwillich $\mathrm{C}$ : The obesity hypoventilation syndrome. Am J Med 2005, 118:948-956.

44. Sullivan CE, Berthon-Jones M, Issa FG: Remission of severe obesity-hypoventilation syndrome after short-term treatment during sleep with nasal continuous positive airway pressure. Am Rev Respir Dis 1983, 128:177-181.

45. Perez de Llano LA, Golpe R, Ortiz Piquer M, Veres Racamonde A, Vazquez Caruncho M, Caballero Muinelos O, Alvarez Carro C: Short-term and long-term effects of nasal intermittent positive pressure ventilation in patients with obesity-hypoventilation syndrome. Chest 2005, 128:587-594.

46. Pepin JL, Chouri-Pontarollo N, Tamisier R, Levy P: CheyneStokes respiration with central sleep apnoea in chronic heart failure: proposals for a diagnostic and therapeutic strategy. Sleep Med Rev 2006, 10:33-47.

47. Teschler H, Dohring J, Wang YM, Berthon-Jones M: Adaptive pressure support servo-ventilation: a novel treatment for Cheyne-Stokes respiration in heart failure. Am J Respir Crit Care Med 2001, 164:614-619.

48. Arzt M, Bradley TD: Treatment of sleep apnea in heart failure. Am J Respir Crit Care Med 2006, 173:1300-1308.

49. Bradley TD, Logan AG, Kimoff RJ, Series F, Morrison D, Ferguson $\mathrm{K}$, Belenkie I, Pfeifer M, Fleetham J, Hanly P, et al.: Continuous positive airway pressure for central sleep apnea and heart failure. N Engl J Med 2005, 353:2025-2033.

50. Gay PC, Herold DL, Olson EJ: A randomized, double-blind clinical trial comparing continuous positive airway pressure with a novel bilevel pressure system for treatment of obstructive sleep apnea syndrome. Sleep 2003, 26:864-869.

51. Trang H, Dehan M, Beaufils F, Zaccaria I, Amiel J, Gaultier C; French CCHS Working Group: The French Congenital Central Hypoventilation Syndrome Registry: general data, phenotype, and genotype. Chest 2005, 127:72-79.

52. Schonhofer B, Geibel M, Sonneborn M, Haidl P, Kohler D: Daytime mechanical ventilation in chronic respiratory insufficiency. Eur Respir J 1997, 10:2840-2846

53. Fauroux B, Nicot F, Essouri S, Hart N, Clement A, Polkey MI, Lofaso F: Setting of noninvasive pressure support in young patients with cystic fibrosis. Eur Respir J 2004, 24:624-630.

54. Vitacca M, Nava S, Confalonieri M, Bianchi L, Porta R, Clini E, Ambrosino $\mathrm{N}$ : The appropriate setting of noninvasive pressure support ventilation in stable COPD patients. Chest 2000, 118: 1286-1293.

55. Fanfulla F, Delmastro M, Berardinelli A, Lupo ND, Nava S: Effects of different ventilator settings on sleep and inspiratory effort in patients with neuromuscular disease. Am J Respir Crit Care Med 2005, 172:619-624.

56. Lofaso F, Quera-Salva MA: Polysomnography for the management of progressive neuromuscular disorders. Eur Respir $J$ 2002, 19:989-990.

57. Appendini L, Patessio A, Zanaboni S, Carone M, Gukov B, Donner CF, Rossi A: Physiologic effects of positive end-expiratory pressure and mask pressure support during exacerbation of chronic obstructive pulmonary disease. Am J Respir Crit Care Med 1994, 149:1069-1076.

58. Johnson KG, Johnson DC: Bilevel positive airway pressure worsens central apneas during sleep. Chest 2005, 128:2141. 2150. 
59. Mehta S, McCool FD, Hill NS: Leak compensation in positive pressure ventilators: a lung model study. Eur Respir J 2001, 17:259-267.

60. Thys F, Liistro G, Dozin O, Marion E, Rodenstein DO: Determinants of $\mathrm{Fi}, \mathrm{O} 2$ with oxygen supplementation during noninvasive two-level positive pressure ventilation. Eur Respir J 2002, 19:653-657.

61. Tzeng AC, Bach JR: Prevention of pulmonary morbidity for patients with neuromuscular disease. Chest 2000, 118:13901396.

62. Curran FJ, Colbert AP: Ventilator management in Duchenne muscular dystrophy and postpoliomyelitis syndrome: twelve years' experience. Arch Phys Med Rehabil 1989, 70:180-185.

63. Cazzolli PA, Oppenheimer EA: Home mechanical ventilation for amyotrophic lateral sclerosis: nasal compared to tracheostomy-intermittent positive pressure ventilation. $J$ Neurol Sci 1996, 139(Suppl):123-128.

64. Hayashi $H$, Oppenheimer EA: ALS patients on TPPV: totally locked-in state, neurologic findings and ethical implications. Neurology 2003, 61:135-137.

65. Polkey MI, Lyall RA, Davidson AC, Leigh PN, Moxham J: Ethical and clinical issues in the use of home non-invasive mechanical ventilation for the palliation of breathlessness in motor neurone disease. Thorax 1999, 54:367-371.

66. Bach JR, Robert D, Leger $P$, Langevin B: Sleep fragmentation in kyphoscoliotic individuals with alveolar hypoventilation treated by NIPPV. Chest 1995, 107:1552-1558.

67. Teschler H, Stampa J, Ragette R, Konietzko N, Berthon-Jones M: Effect of mouth leak on effectiveness of nasal bilevel ventilatory assistance and sleep architecture. Eur Respir J 1999, 14: 1251-1257.

68. Mehta S, Hill NS: Noninvasive ventilation. Am J Respir Crit Care Med 2001, 163:540-577.

69. Richards GN, Cistulli PA, Ungar RG, Berthon-Jones M, Sullivan $\mathrm{CE}$ : Mouth leak with nasal continuous positive airway pressure increases nasal airway resistance. Am J Respir Crit Care Med 1996, 154:182-186.

70. Randerath WJ, Meier J, Genger H, Domanski U, Ruhle KH: Efficiency of cold passover and heated humidification under continuous positive airway pressure. Eur Respir J 2002, 20: 183-186.

71. Hill NS: Complications of noninvasive ventilation. Respir Care 2000, 45:480-481.

72. Strumpf DA, Millman RP, Carlisle CC, Grattan LM, Ryan SM, Erickson AD, Hill NS: Nocturnal positive-pressure ventilation via nasal mask in patients with severe chronic obstructive pulmonary disease. Am Rev Respir Dis 1991, 144:1234-1239.

73. Barbe F, Quera-Salva MA, de Lattre J, Gajdos P, Agusti AG: Long-term effects of nasal intermittent positive-pressure ventilation on pulmonary function and sleep architecture in patients with neuromuscular diseases. Chest 1996, 110:11791183.

74. Schonhofer B, Kohler D: Effect of non-invasive mechanical ventilation on sleep and nocturnal ventilation in patients with chronic respiratory failure. Thorax 2000, 55:308-313.

75. Carrey Z, Gottfried SB, Levy RD: Ventilatory muscle support in respiratory failure with nasal positive pressure ventilation. Chest 1990, 97:150-158.

76. Karakurt S, Fanfulla F, Nava S: Is it safe for patients with chronic hypercapnic respiratory failure undergoing home noninvasive ventilation to discontinue ventilation briefly? Chest 2001, 119:1379-1386.

77. Lin CC: Comparison between nocturnal nasal positive pressure ventilation combined with oxygen therapy and oxygen monotherapy in patients with severe COPD. Am J Respir Crit Care Med 1996, 154:353-358.

78. Markstrom A, Sundell K, Lysdahl M, Andersson G, Schedin U, Klang B: Quality-of-life evaluation of patients with neuromuscular and skeletal diseases treated with noninvasive and invasive home mechanical ventilation. Chest 2002, 122: 1695-1700.

79. Budweiser S, Heinemann F, Fischer W, Dobroschke J, Wild PJ Pfeifer M: Impact of ventilation parameters and duration of ventilator use on non-invasive home ventilation in restrictive thoracic disorders. Respiration 2006, 73:488-494.

80. Elliott MW, Mulvey DA, Moxham J, Green M, Branthwaite MA: Domiciliary nocturnal nasal intermittent positive pressure ventilation in COPD: mechanisms underlying changes in arterial blood gas tensions. Eur Respir J 1991, 4:1044-1052.

81. Nickol AH, Hart N, Hopkinson NS, Moxham J, Simonds A, Polkey $\mathrm{Ml}$ : Mechanisms of improvement of respiratory failure in patients with restrictive thoracic disease treated with noninvasive ventilation. Thorax 2005, 60:754-760.

82. Simonds AK, Parker RA, Branthwaite MA: The effect of intermittent positive-pressure hyperinflation in restrictive chest wall disease. Respiration 1989, 55:136-143.

83. Lechtzin N, Shade D, Clawson L, Wiener CM: Supramaximal inflation improves lung compliance in subjects with amyotrophic lateral sclerosis. Chest 2006, 129:1322-1329.

84. Schonhofer B, Barchfeld T, Wenzel M, Kohler D: Long term effects of non-invasive mechanical ventilation on pulmonary haemodynamics in patients with chronic respiratory failure. Thorax 2001, 56:524-528.

85. Meecham Jones DJ, Paul EA, Jones PW, Wedzicha JA: Nasal pressure support ventilation plus oxygen compared with oxygen therapy alone in hypercapnic COPD. Am J Respir Crit Care Med 1995, 152:538-544. 